Review

\title{
Dual-Targeting for the Elimination of Cancer Cells with Increased Selectivity
}

\author{
Ingo Schubert ${ }^{1, \dagger}$, Christoph Stein ${ }^{2, \dagger}, *$ and Georg H. Fey ${ }^{1}$
}

1 Department of Biology, University of Erlangen-Nuremberg, Erlangen 91058, Germany; E-Mails: ischuber@biologie.uni-erlangen.de (I.S.); gfey@biologie.uni-erlangen.de (G.H.F.)

2 Department of Experimental Medicine and Immunotherapy, Institute of Applied Medical Engineering, Helmholtz Institute, RWTH, Aachen 52074, Germany

$\dagger$ These authors contributed equally to this work.

* Author to whom correspondence should be addressed; E-Mail: stein@hia.rwth-aachen.de; Tel.: +49-241-6085-13442; Fax: +49-241-6085-10000.

Received: 28 February 2012; in revised form: 16 March 2012 / Accepted: 30 March 2012 / Published: 10 April 2012

\begin{abstract}
Here we review recombinant proteins with a capability for dual-targeting. These molecules address two different antigens on the same tumor cell and therefore are called "dual-targeting agents". By virtue of binding a chosen pair of antigens on the malignant cell, preferential binding to antigen double-positive over single-positive cells can be achieved when both are present in the same environment. Therapeutic effects of such agents are based on different modes of action: (1) They can act as pro-apoptotic agents or by inhibiting pro-survival signals; (2) The dual recognition moiety can be fused to effector-domains, such as bacterial toxins or other drugs, leading to the generation of bispecific antibody-drug conjugates (ADCs); (3) Dual-targeting agents can further be used to redirect an effector-cell to the tumor. A new generation of scFv-derived fusion proteins are the tandem single chain triplebodies (sctbs), which carry two scFv binding sites for antigens on the tumor cell plus a third, specific for a trigger molecule on an effector cell. The ability of preferential or selective targeting of antigen double-positive over singlepositive cells opens attractive new perspectives for the use of dual-targeting agents in cancer therapy, and possibly also for the treatment of certain inflammatory and autoimmune disorders.
\end{abstract}


Keywords: dual-targeting; cancer therapy; effector cell; triplebody; NK-cell; macrophage; drug conjugates

\section{Introduction}

Antibodies have become an integral part of therapeutic protocols for several malignancies, including both hematologic diseases and solid tumors such as breast and colon cancers [1-3]. Monoclonal antibodies have clearly improved treatment outcome but, most often, they do not cure patients as single agents. Response rates remain unsatisfactory, and relapse still presents a serious problem. The limitations of unmodified immunoglobulins (Igs) as therapeutic agents are due in part to the fact that relevant antigens such as the EGF receptor (EGFR), epithelial cell adhesion molecule (EpCAM), melanoma-associated chondroitin sulfate proteoglycan (MCSP), prostate specific membrane antigen (PSMA), diganglioside GD2 and others, which are attractive targets for the treatment of solid cancers, often have a broad tissue distribution and, therefore, may cause undesirable side effects when targeted by antibody-derived therapeutics [4-9].

To develop more specific and potent antibody-derived agents, a possible solution may arise from going beyond the format of intact Igs. To this effect, a number of recombinant antibody-derived formats have been developed including immunotoxins, radio-immunoconjugates, bispecific immunoglobulins, bispecific single-chain Fv antibody-derivatives, so-called bsscFvs, and tandem single chain triplebodies (sctbs) [10-13]. A recently approved bispecific full-length antibody is catumaxomab (Removab ${ }^{\circledR}$ ), a hybrid Ig with one binding site each for EpCAM and CD3, which was approved for the treatment of malignant ascites [7]. An example for the bsscFv format is blinatumomab, a recombinant fusion protein comprising scFvs specific for CD19 on malignant B-lymphoid cells and CD3 on effector $\mathrm{T}$ lymphocytes [14]. This agent produced encouraging clinical responses against non-Hodgkin lymphoma (NHL) and pediatric acute lymphoblastic leukemia (ALL) [4,15]. Additional agents in the same so-called BiTE format (bispecific T-cell engaging agents) are under development [16]. In face of the outstanding results a major disadvantage of the BiTE format is the short plasma retention time requiring an administration as a 4-week continuous infusion. Due to this application form, the therapy is associated with side effects for the majority of patients [14]. BsscFvs have a relative molecular mass of only about $50-60 \mathrm{kDa}$, and such small proteins are rapidly cleared from the bloodstream by the kidneys [17,18]. Due to the missing Fc-portion, bsscFvs also lack the interaction domain for the neonatle Fc-receptor (FcRn), which is involved in the recirculation of IgGs [19]. To overcome this problem, a number of improvements could be made. The size can be increased by modifications such as PEGylation or the addition of an extra $\mathrm{scFv}[20,21]$. By addition of protein domains like the human serum albumin, the interaction with the FcRn can be enabled [22]. All these modifications resulted in an improvement of the plasma retention time and body retention time in vivo [23]. However, all of these agents are monospecific for the tumor cell and cannot discriminate between malignant and healthy cells carrying the same target antigen. To overcome this disadvantage, some investigators focused their work on recombinant agents with increased selectivity for the malignant cell. To achieve this goal the idea was to target a tumor-specific pair of antigens on the same cell. Ring 
and colleagues developed the first dual-targeting agent, a so called antigen fork (Figure 1A), by crosslinking two antibodies with different specificities for a pair of antigens on the same tumor cell [24]. Several other strategies followed over the next years to achieve increased selectivity, all using a common principle: A combination of several antibody-derived binding sites for the simultaneous targeting of more than one different antigen on the surface of the same cancer cell (Figure 1; Table 1).

Figure 1. Schematic structure of dual-targeting agents. (A) cross linked monoclonal antibodies (antigen fork); (B) chemically coupled F(ab')-fragments; (C) two F(ab') chemically coupled to a human IgG (HexAb); (D) tandem bispecific single chain Fragment variable (bsscFv); (E) tetravalent bispecific antibody (EI-04), two scFvs genetically fused to a human Immunoglobulin G (IgG); (F) DT-Ig consisting of the variable region of the heavy chain and the light chain of two different antibodies, cloned in frame to an IgG; (G) heteromeric peptide coupled to a human IgG (CovX-body; CVX-241); (H) scFvs fused to a Fc-domain on both termini; (I) two antigen combining sites with different specificity in tandem on an IgG (DVD-IgG); (J) tandem trispecific sctb; (K) coupled F(ab') ${ }_{3}$-fragment.

A

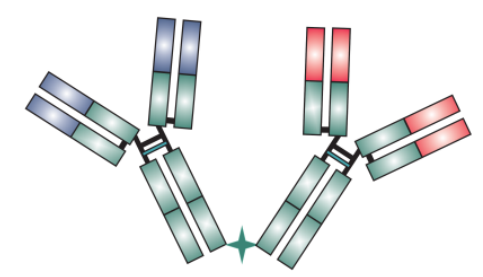

B

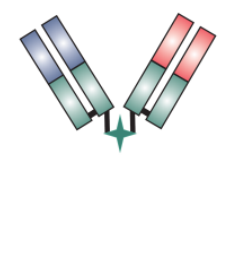

$\mathrm{C}$

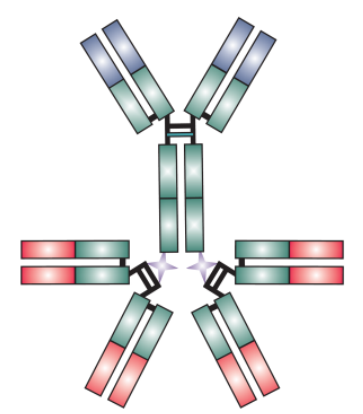

$\mathrm{H}$

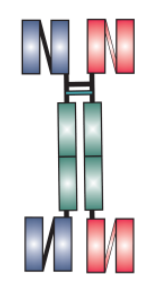

I

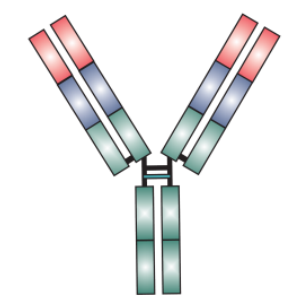

$\mathrm{D}$

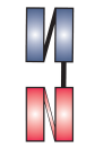

E

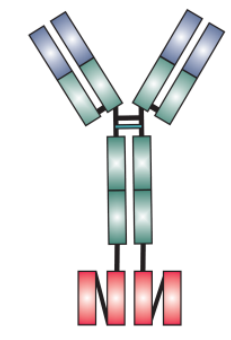

$\mathrm{J}$

K
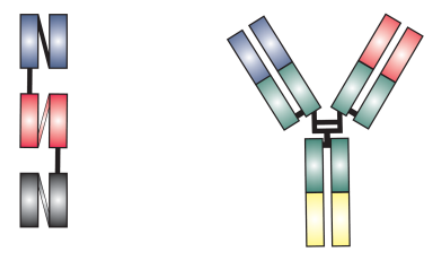

Tabel 1. Dual-targeting molecules.

\begin{tabular}{lccccc}
\hline Format & \multicolumn{1}{c}{ Specificity } & Disease & Function & Company & Ref. \\
\hline \multicolumn{1}{l}{ Bispecific agents without intrinsic effector } & domain & & & \\
\hline $\mathrm{F}(\mathrm{ab})_{2}$ & $\mathrm{CD} 20 / \mathrm{CD} 22$ & B-ALL & Signaling & - & {$[25]$} \\
$\mathrm{Bs}-\mathrm{scF} V$ & ErbB2/ErbB3 & Breast cancer & Signaling & - & {$[26]$} \\
$\mathrm{HexAb}$ & $\mathrm{CD} 20 / \mathrm{CD} 74$ & Lymphoma & Signaling & Immunomedics IBC & {$[27]$} \\
& & & Pharmaceuticals & \\
Two-in-one & HER3/EGFR & Several & Signal & Genentech & {$[28]$} \\
antibody & & carcinomas & inhibition & & \\
\hline
\end{tabular}


Tabel 1. Cont.

\begin{tabular}{|c|c|c|c|c|c|}
\hline Format & Specificity & Disease & Function & Company & Ref. \\
\hline \multicolumn{6}{|c|}{ Bispecific agents without intrinsic effector domain } \\
\hline Tetravalent bs-ab & EGFR/IGF-1R & $\begin{array}{l}\text { Several } \\
\text { carcinomas }\end{array}$ & $\begin{array}{l}\text { Signal } \\
\text { inhibition }\end{array}$ & Biogen Idec & [29] \\
\hline Bs-scFv & ErbB2/ErbB3 & Breast cancer & $\begin{array}{l}\text { Signal } \\
\text { inhibition }\end{array}$ & $\begin{array}{c}\text { Merrimack } \\
\text { Pharmaceuticals }\end{array}$ & {$[30]$} \\
\hline Bispecific diabody & VEGFR2 & $\begin{array}{l}\text { Several } \\
\text { carcinomas }\end{array}$ & $\begin{array}{l}\text { Signal } \\
\text { inhibition }\end{array}$ & - & [31] \\
\hline Bispecific diabody & VEGFR2/VEGFR3 & $\begin{array}{l}\text { Several } \\
\text { carcinomas }\end{array}$ & $\begin{array}{l}\text { Signal } \\
\text { inhibition }\end{array}$ & $\begin{array}{c}\text { ImClone } \\
\text { Systems } \\
\text { Incorporated }\end{array}$ & {$[32]$} \\
\hline Bispecific adnectin & EGFR/IGF-1R & $\begin{array}{l}\text { Several } \\
\text { carcinomas }\end{array}$ & $\begin{array}{l}\text { Signal } \\
\text { inhibition }\end{array}$ & $\begin{array}{c}\text { Bristol-Myers } \\
\text { Squibb/ } \\
\text { Adnexus }\end{array}$ & [33] \\
\hline $\begin{array}{l}\text { Bispecific CovX- } \\
\text { Body (CVX241) }\end{array}$ & VEGF/Ang2 & $\begin{array}{l}\text { Epithelial } \\
\text { Ovarian } \\
\text { cancer or } \\
\text { primary } \\
\text { peritoneal } \\
\text { cancer }\end{array}$ & $\begin{array}{l}\text { Signal } \\
\text { inhibition }\end{array}$ & Pfizer & {$[34]$} \\
\hline Bispecific scFv & PDGFRß/VEGF-A & $\begin{array}{l}\text { Several } \\
\text { carcinomas }\end{array}$ & $\begin{array}{l}\text { Signal } \\
\text { inhibition }\end{array}$ & - & {$[35]$} \\
\hline DVD-IgG & IL-1 $\alpha /$ IL-1 $\beta$ & $\begin{array}{l}\text { Inflammatory } \\
\text { diseases }\end{array}$ & $\begin{array}{l}\text { Signal } \\
\text { inhibition }\end{array}$ & Abbott & {$[36]$} \\
\hline Gold-nanoparticle & $\mathrm{EGFR} / \mathrm{FR} \alpha$ & $\begin{array}{l}\text { ovarian } \\
\text { cancer }\end{array}$ & $\begin{array}{l}\text { Signal } \\
\text { inhibition }\end{array}$ & - & [37] \\
\hline \multicolumn{6}{|l|}{ Retargeting agents } \\
\hline $\left.\mathrm{F}(\mathrm{ab})_{3}\right)_{3}$ & EGFR/Her2/CD64 & $\begin{array}{l}\text { Several } \\
\text { carcinomas }\end{array}$ & Retargeting & Medarex & [38] \\
\hline Triplebody & CD19/CD33/CD16 & MLL & Retargeting & - & [13] \\
\hline Triplebody & CD19/HLAII/CD16 & B-ALL & Retargeting & - & [12] \\
\hline Triplebody & $\mathrm{CD} 123 / \mathrm{CD} 33 / \mathrm{CD} 16$ & AML & Retargeting & SpectraMab & [11] \\
\hline \multicolumn{6}{|l|}{ Toxins } \\
\hline $\begin{array}{l}\text { Ligand-directed } \\
\text { toxin }\end{array}$ & EGFR/IL-4R & $\begin{array}{l}\text { Pancreatic } \\
\text { cancer }\end{array}$ & Toxic & - & {$[39,40]$} \\
\hline Immunotoxin & CD19/CD22 & B-ALL & Toxic & - & [41] \\
\hline $\begin{array}{l}\text { Ligand-directed } \\
\text { toxin }\end{array}$ & EGFR/IL-13R & $\begin{array}{l}\text { Pancreatic } \\
\text { cancer }\end{array}$ & Toxic & - & [40] \\
\hline
\end{tabular}

The table lists agents in advanced stages of preclinical and clinical development, about which information is available in the public domain. They can be divided into three groups: agents of the first group have no intrinsic effector domain and simply consist of a combination of two antigen-combining sites. Their function is mediated by binding antigens which induce intracellular signals or by inhibiting signals emerging from cell-surface receptor or its ligands. Agents of the second group recruit an effector cell to the tumor cell and induce antibody-dependent cellular cytotoxicity (ADCC), also called 
redirected lysis, and or antibody-dependent cellular phagocytosis (ADCP). The last mode of action is the delivery of a toxin, a drug or another death-inducing agent, such as a caspase, an siRNA, an RNAse or another pro-apoptotic agent, to drive the cancer cell to its demise (Figure 2).

Figure 2. Modes of action mediated by dual-targeting molecules. Blocking of intracellular pathways by a, dual receptor-binding or $b$, dual ligand-binding (on the right site). Binding to a pair of receptors leads to the induction of anti-proliferative and/or pro-apoptotic signals for suitable chosen combinations. Dual-targeted import of a cytotoxic component directly eliminates the target cell. Recruiting of effector cells to the target cells by dual-recognition mediates antibody-dependent cellular cytotoxicity (ADCC) or antibody-dependent cellular phagocytosis (ADCP).

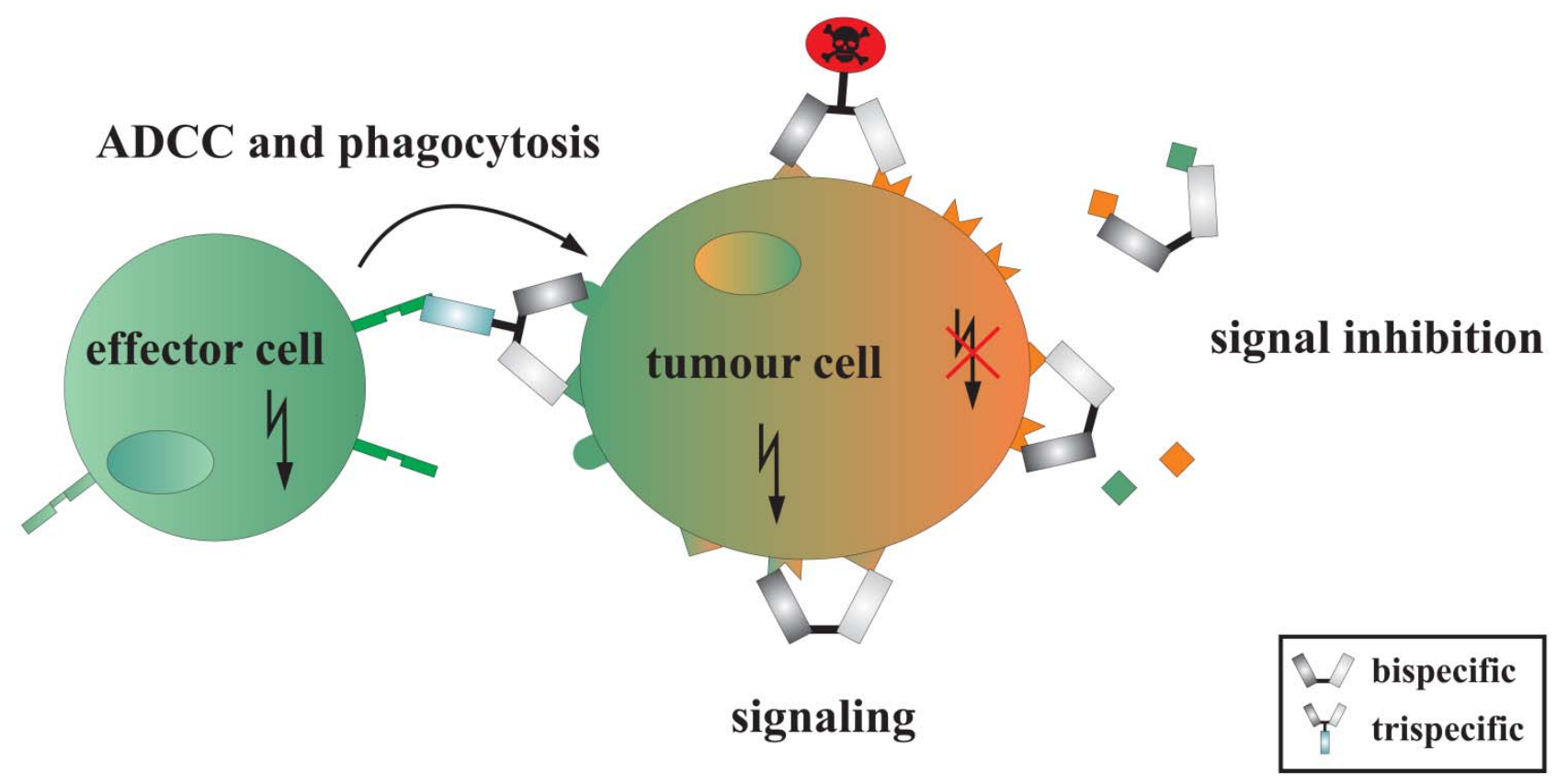

\section{Dual-Targeting Agents}

\subsection{Induction and Inhibition of Intracellular Signals by Dual-Targeting Agents}

Mediated by the interaction of an antibody with a cell surface receptor or a ligand, the transduction of signals can be induced or blocked, leading to cellular growth arrest or apoptosis. Two examples of agents inducing such signals are first a $\mathrm{F}(\mathrm{ab})_{2}$ (Figure 1B), designed for the treatment of B-ALL. This compound simultaneously binds CD20 and CD22 on the malignant cell and thereby mediates apoptosis [25]. Secondly, Gupta et al. obtained enhanced cytotoxicity for biopsy material from patients with mantle cell lymphoma (MCL) and for cell lines derived from leukemias and lymphomas, by using a bispecific hexavalent antibody (HexAb; Figure 1C) targeting CD20 and CD74, compared to treatment with the parental monoclonal antibodies, used either alone or in combination [27]. Anti-proliferative signaling through the epidermal growth factor receptor (EGFR) and ErbB2/HER2 members of the EGFR-family has been noted to occur in a variety of cancers. A bispecific scFv (bsscFv; Figure 1D) and a bispecific antibody (bsAb) simultaneously targeting ErbB2 and ErbB3 
showed increased selectivity for binding to antigen double-positive over single-positive cells [26]. In preclinical models the agents displayed antitumor activities depending on the degree of overexpression of ErbB2 [30]. Vascular endothelial growth factors (VEGF) and their receptor (VEGFR) play important roles in tumor-associated angiogenesis, tumor growth and metastasis. Two bispecific diabodies directed against the VEGFR have been reported. In one case, Lu et al. generated scFvs with specificity for VEGFR2. To construct their first diabody, these authors used two different scFv-binding domains with increased affinity and decreased dissociation rate relative to the parental scFvs [31]. The resulting bispecific diabody directed against VEGFR2 and VEGFR3 neutralized VEGF-stimulated activation and inhibited VEGF-induced migration of endothelial cells [32].

Engineered domains of human fibronectin with the ability to serve as ligands for growth factor receptors (Adnectins ${ }^{\mathrm{TM}}$ ) were used by other authors to generate a bispecific Adnectin targeting EGFR and insulin-like growth factor-I receptor (IGF-IR). This agent inhibited the phosphorylation of EGFR and IGF-IR, induced receptor degradation, and therefore blocked downstream signaling and proliferation of various human cancer cell lines [33]. However, this is not an example of an antibodyderived agent, but simply of a synthetic fusion peptide with dual specificity, binding two different critical receptors on a tumor cell and thereby inducing an antitumor effect.

Another team of investigators designed a stable IgG-like bsAb for dual-targeting of the EGF- and IGF-1 receptors. This bsAb, EI-04, was constructed with a stability-engineered scFv specific for IGF-1R, attached to the C-terminus of an EGFR-specific IgG. The format is therefore that of a bispecific, tetravalent scFv-IgG fusion protein (Figure 1E). EI-04 displayed favorable biophysical properties for biopharmaceutical development. In tumor cells, the agent effectively inhibited the phosphorylation of EGFR and IGF-1R, and blocked the activation of the downstream kinases AKT and ERK, resulting in greater inhibition of tumor cell growth and cell cycle progression than the degree achieved by the corresponding monoclonal antibodies, used either alone or in combination [29].

DT-IgGs are recombinant humanized dual-targeting immunoglobulins developed to simultaneously target, e.g., EGFR and VEGF. One DT-IgG was generated by introducing anti-VEGF and anti-EGFR domain antibodies onto the heavy and light chains, respectively, of an IgG1 constant region (Figure 1F). When studied in nude mice bearing human tumor xenografts, this prototype DT-IgG showed favorable pharmacodynamic properties and promising anti-tumor activity [42].

An astounding new format is "two-in-one" IgGs. The prototype of this format is an IgG molecule with sophisticated mutations in its variable region, that endow the same variable region with specific binding to both HER3 and the EGFR [28]. This novel format therefore violates Jerne's fundamental principle positing that one antibody generated by a vertebrate immune system in vivo have only one specificity. Such "two-in-one" antibodies therefore are total artifacts, which would not normally arise in a healthy vertebrate immune system in vivo. The prototype was designed for the treatment of carcinomas and inhibited EGFR- and HER3-mediated signaling both in vitro and in vivo. It also inhibited the ability of the target cell to recruit immune effector functions. The "two-in-one" agent had broader efficacy in multiple tumor models than the corresponding monospecific antibodies [28].

CovX-Bodies are antibody-fusion proteins carrying artificial target binding ligands fused to their N-termini. For the prototype CovX-body CVX241 (Figure 1G) Doppalapudi and colleagues [34] used two chemically-linked peptide ligands specific for VEGF and Angiopoietin 2 (Ang2). One copy each of this pair of linked peptides was coupled to the N-terminus of a carrier antibody. This carrier, 
however, did not contribute to the antigen recognition function, but solely served as a scaffold to hold these targeting peptides in place in a suitable geometrical arrangement, and to recruit the classical effector functions of IgG Fc-domains. Due to simultaneous binding to VEGF and Ang2 the agent interfered with the function to these target factors and showed efficacy in a tumor xenograft model [34].

A promising approach for the treatment of solid tumors is to target angiogenesis, and the combination of two mAbs has the potential to increase the efficacy of an anti-angiogenic therapy. Therefore, scFvs directed against PDGFR $\beta$ and VEGF-A were fused to both termini of a human Fc-domain to generate a bispecific, tetravalent molecule (Figure $1 \mathrm{H}$ ). This recombinant fusion protein indeed had dual-targeting capacity and displayed potent activity. It bound both antigens and was stable in serum [35].

For complex diseases, in which multiple mediators are involved, a simultaneous blockade of multiple targets may result in a better therapeutic effect than the inhibition of a single target. To study this concept, the company Abbott developed the dual variable domain immunoglobulin (or DVD-Ig) format, which allows the incorporation of the distinct specificities of two monoclonal antibodies into a single dual-specific IgG-like molecule [43]. These agents carry two conventional antigen combining sites with different specificity arranged in tandem on each of the two arms of the IgG to generate a tetravalent overall affinity (Figure 1I). Signal transduction through the interleukin-1 receptor (IL-1R) mediates a strong pro-inflammatory response, which contributes to a number of human diseases. By blocking interleukins IL- $1 \alpha$ and IL-1 $\beta$ with an anti-human IL-1 $\alpha$ / $\beta$ DVD-Ig molecule, the production of pro-inflammatory IL-8 was inhibited and favorable anti-inflammatory effects were achieved [36].

\subsection{Retargeting Agents}

The second group of dual-targeting agents recruits effector cells to the tumor cell and mediates ADCC and/or phagocytosis. Single-chain triplebodies carry three scFvs arranged in tandem in a single polypeptide chain (Figure 1J). A centrally placed binding domain for the Fc gamma receptor IIIa (CD16) is flanked in this format by scFvs with specificities for two different antigens on the same malignant cell. The first published dual-targeting sctb, sctb 123-ds16-33, consists of scFv binding modules for CD123 and CD33 on the tumor cell and CD16 on the effector cell. The prefix "ds" signifies a disulfide-stabilized scFv-component [44]. This sctb was designed for preferential targeting of AML-leukemic stem cells (AML-LSC) over bulk AML cells and healthy hematopoietic stem cells, because AML-LSCs carry approximately 5- to 10-fold greater surface densities of CD123, the $\alpha$-chain of the interleukin-3 receptor, than these other cell populations [45,46]. Sctbs in general represent an improvement over the corresponding bispecific scFvs, carrying only one binding site for the cancer cell and one for the trigger on the effector cell [10]. In the sctb-format the scFvs specific for the tumor cell flank the scFv specific for a trigger-molecule expressed on the effector cell. Unique features of sctbs include an increased affinity/avidity for the tumor cell over the corresponding bispecific scFvs [47], a longer plasma retention time [10] and the ability for dual-targeting. Remarkably, the gain in binding-strength always resulted in a more-than-proportional gain in cytolytic activity, often by more than an order of magnitude. This observation was made for several different sctbs and invited the speculation, that triplebodies may either form particularly effective immunological synapses between the tumor- and effector cells, or trigger a particularly potent response 
by the effector cell, or mediate a combination of these effects. Immunofluorescence studies confirmed that all three scFvs carried in the sctb 123-ds16-33 were functional and able to bind their respective antigens. ADCC-experiments also confirmed the claim that both of the anti-tumor scFvs contributed to the cytotoxic effect. This result was achieved by separately blocking the binding of sctb 123-ds16-33 to an AML-derived cell line or to the effector cells with a molar excess of corresponding scFvs and a CD16-directed monoclonal antibody, respectively. Blocking led to a strong decrease of the cytotoxic effect confirming the specific interaction of all three binding moieties with their cognate targets and the need for all three of these interactions to achieve maximum cytotoxic effects (Figure 3 ).

Figure 3. Antigen-specific induction of ADCC in the double-positive AML cell-line MOLM-13 by sctb 123-ds16-33. The sctb induced strong ADCC of MOLM-13 cells at a concentration of $1 \mathrm{nM}$. Simultaneous addition of a 500-fold molar excess of CD33- and CD123-specific scFvs each completely blocked the ADCC reaction, but the addition of either the CD33- or the CD123-specific scFv alone, or a control scFv, did not. Simultaneous incubation with a 125-fold molar excess of a CD16-specific antibody-but not with a control IgG1 - significantly reduced ADCC. Data points represent mean percentage of relative specific lysis obtained with isolated mononuclear cells (MNCs) from six different unrelated healthy human donors at an E:T ratio of 40:1. Specific lysis measured for the sctb was set to $100 \%$, background lysis occurring in the absence of added sctb or antibody $(\mathrm{Ab})$ was defined as $0 \%$, and specific lysis was calculated as total minus spontaneous lysis. The * symbol designates statistically significant differences $(p<0.05)$ in ADCC relative to the control sctb. From Kügler 2011 [11] with permission.

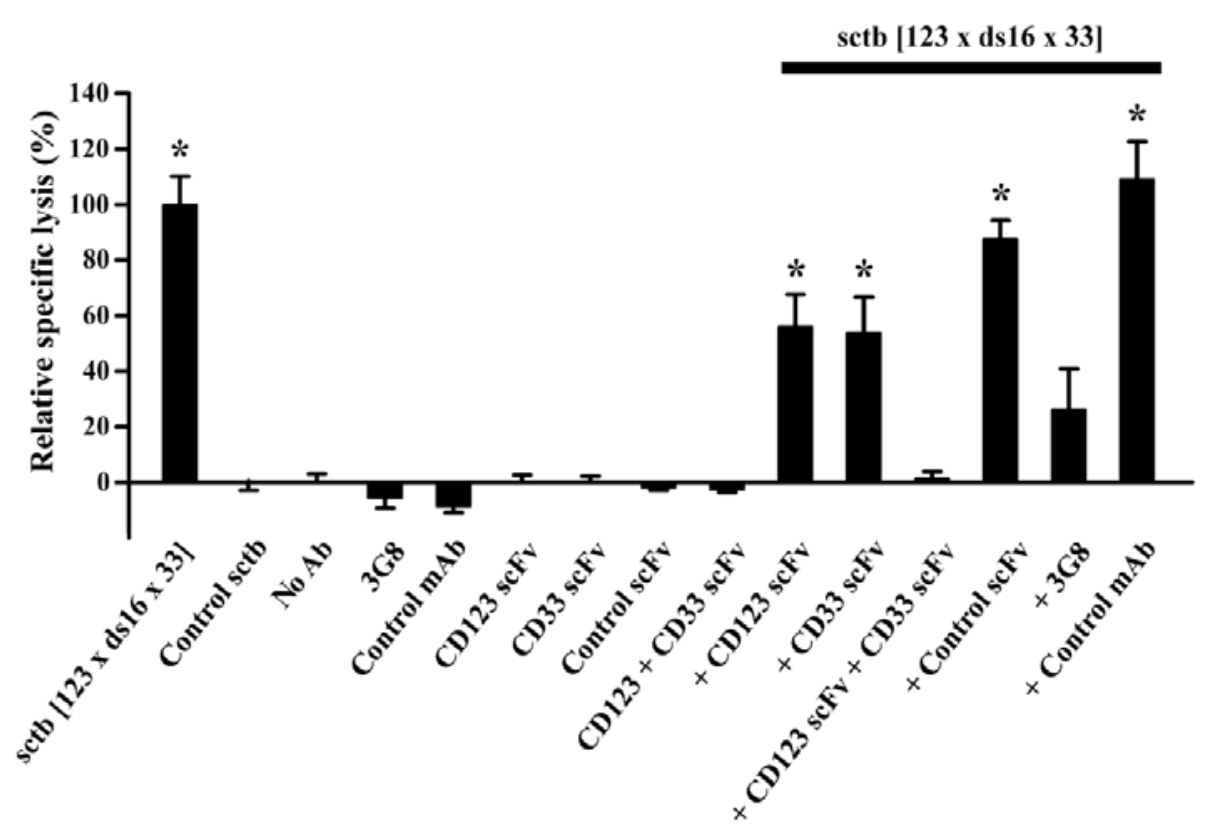

In cytotoxicity experiments with primary AML cells, freshly obtained from leukemia patients, the sctb produced stronger lysis than the mono-targeting counterparts, sctb 123-ds16-123 and sctb 33-ds16-33, respectively. Although statistical significance has not yet been reached for the differences between the dual- and the mono-targeting agents, the results provide a first indication for a potential benefit of dual- over mono-targeting sctbs (Figure 4) [11]. Current efforts are directed at testing the 
hypothesis, that the benefits may become more obvious for target cell populations enriched in CD34-positive AML-LSCs, because these cells carry greater surface densities of CD123.

Figure 4. Lysis of primary AML cells by the dual-targeting sctb 123-ds16-33 and the mono-targeting control-molecules 123-ds16-123 and 33-ds16-33. Sctbs 123-ds16-33 (closed triangles), 123-ds16-123 (open circles) and 33-ds16-33 (open triangles) mediated dose-dependent ADCC of primary AML cells, whereas a control sctb (closed squares) failed to achieve this result. Target cells were primary cells from the peripheral blood of six different AML patients, diagnosed with AML of different subtypes. Data points represent mean percentage of specific lysis averaged over the six patients, obtained with isolated MNCs from one healthy donor per patient sample at an E:T ratio of 40:1. Specific lysis is total minus spontaneous lysis. From Kügler 2011 [11] with permission.

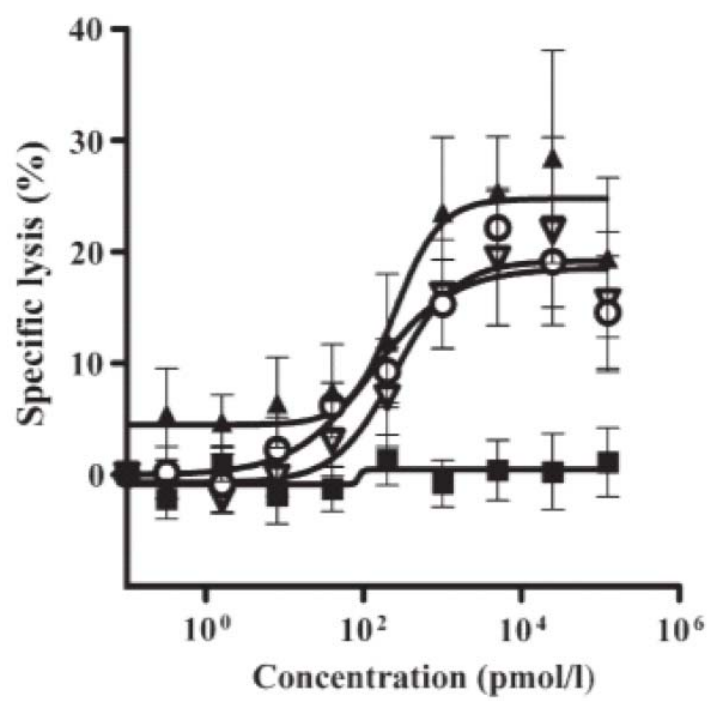

Two additional sctbs have been produced and studied, which further illustrate unique functional capabilities offered by dual-targeting, the sctbs 33-ds16-ds19 and HLA-ds16-hu19. The prefix "hu" signifies a murine scFv humanized by CDR-grafting plus additional point mutagenesis [48]. The first of these two sctbs, 33-ds16-ds19, was designed for the treatment of mixed lineage leukemias (MLL), also called bi-phenotypic leukemia. Blasts from patients with these disorders show a characteristic combination of phenotypic markers, usually found exclusively in a healthy hematopoietic system in either lymphoid or myeloid cells. Typical examples of mixed-lineage leukemias are high risk leukemias associated with characteristic chromosomal rearrangements of the MLL locus on human chromosome 11q23, such as the translocations $\mathrm{t}(4 ; 11), \mathrm{t}(9 ; 11)$ or $\mathrm{t}(11 ; 19)$. These leukemic blasts often show both lymphoid markers, including CD19 and CD22, and myeloid markers such as CD13, CD33 on the same cells. These combinations are not observed on healthy hematopoietic cells, which commit either to the lymphoid or the myeloid lineage, but as a rule do not show a mixed lineage phenotype [49, 50]. Therefore the mixed lineage phenotype offered a unique opportunity to selectively target the tumor cells over healthy normal cells, provided an agent could be constructed, which preferentially targeted this combination. Indeed, both the distal tumor-antigen binding sites of sctb 33-ds16-ds19 were capable of binding their cognate antigens, and simultaneous occupation of all three binding sites was demonstrated in binding studies [13]. In ADCC-experiments the sctb reached equal cytotoxicity for an 
antigen double-positive leukemic cell line at lower concentrations than mono-targeting agents directed against either CD33 or CD19 alone [13]. Therefore, this sctb indeed was capable of employing both its distal binding sites for binding to one each of these antigens on the same tumor cell and thus in principle should be capable of preferential binding to antigen double-positive MLL cells over singlepositive controls. For this particular sctb this key experiment however has not yet been performed.

Preferential binding to antigen double-positive cells has however been demonstrated for the triplebody HLA-ds16-hu19 in a model situation set up to show this effect as clearly as possible. In these experiments (HLA-DR- plus CD19-) double-positive SEM leukemic cells were mixed with increasing numbers of HLA-DR single-positive HUT-78 leukemic cells, and the mixtures were incubated with the sctb in sub-saturating amounts. Binding was monitored by cytofluorometry using a red fluorescent-labeled second antibody specifically reacting with the sctb. When both cell types were mixed in a 1:1 ratio, and the sctb administered in suitably titrated sub-saturating amounts, then almost all of the double-positive cells, but only a little more than half of the single-positive cells, were decorated with the sctb (Figure 5A,B). Even when the single-positive cells were present in a 10- and 20-fold numerical excess over the double-positive cells, the sctb reacted preferentially with the double-positive cells (Figure 5C,D).

Figure 5. Triplebody HLA-ds16-hu19 preferentially binds antigen double-positive cells by virtue of dual-targeting. SEM cells (double-positive for CD19- and HLA-DR) were loaded with the fluorescent label Calcein (green) and mixed with unlabeled HUT-78 cells (single-positive for HLA-DR). The mixing ratio was 1:1 for panels A and B and 1:10 or 1:20 for panels $\mathbf{C}$ and $\mathbf{D}$, respectively. Mixtures were incubated with phosphate buffer containing albumin (PBA, panel A) or the sctb (B-D). Fluorescent labeled SEM cells free of decorating sctb were detected in the upper left quadrant, the unstained free HUT-78 cells in the lower left quadrant. Cells decorated with the sctb shifted to the right quadrants. Numbers represent the percentage of the cells in the respective quadrants. From Schubert 2012 [12] with permission.

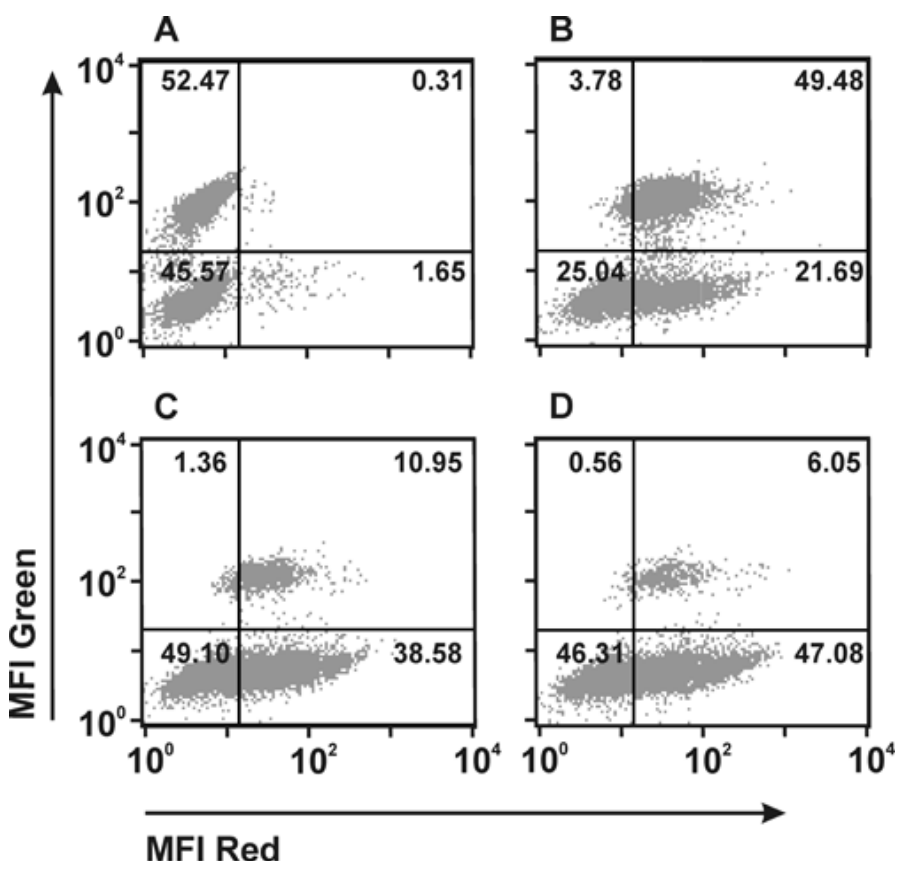


This demonstration was extended to show not only preferential binding to double-positive cells, but also preferential elimination of double-positive cells by NK-cell containing effector populations in cytotoxicity tests. In a redirected lysis (ADCC) assay equal numbers of the same single- and double-positive target cells as above were employed. In this experiment one cell-population was labeled with ${ }^{51} \mathrm{Cr}$, the other remained unlabeled, and both reciprocal constellations were studied. In this setting, approximately $2 / 3$ of the double-positive cells were eliminated but only about $1 / 3$ of the singlepositives, when the effector cells (MNC fraction containing NK cells as the relevant population) were added in a 40:1 ratio over the target cells [12]. The precise extent of lysis of the two target subpopulations depended on the effector-to-target cell ratio (E:T), the concentration of the sctb, and the activation status of the effector cells. Under the most favorable conditions, when interleukin-2 stimulated enriched NK-cell fractions were used as effectors, up to $80 \%$ of the double-positive cells were eliminated but only $20 \%$ of the single positives [51].

These data represent a favorable situation set up to demonstrate the effect with maximum clarity, because these target cell lines were carefully chosen to carry the two target antigens in closely similar surface densities. In a clinical situation this is often not the case, and one antigen can be present at ten-fold greater density on the same cell than the other. This is often the case for primary AML cells and AML-derived cell lines for the antigens CD123 and CD33. Therefore, for the clinically attractive sctb 123-ds16-33, preferential elimination of double-positive target cells has not yet been demonstrated with similar clarity. The attempts were hampered so far by the fact, that on most primary isolates of AML cells freshly drawn from patients and on most of the commonly used AML-derived stable cell lines, CD33 is present in far greater surface density than CD123. Current efforts are directed at finding a pair of target cell lines permitting the analogous experiments, and preliminary data suggests that the CD33 single-positive pro-myelocytic line U937 and the double-positive line MOLM-13 may be suited for the purpose. Therefore, the number of cases in which preferential elimination of antigen doublepositive cells by dual-targeting sctbs can clearly be demonstrated will likely increase in the future.

The unique features of sctbs, such as the capability for dual-targeting, modular design, ability to mediate potent $\mathrm{ADCC}$, useful plasma retention times, good stability and simple production and purification-processes using industry standard methods, make them very promising tools for the therapy of different malignancies as well as certain inflammatory- and autoimmune-disorders.

A dual-targeting $\mathrm{F}\left(\mathrm{ab}^{\prime}\right)_{3}$ antibody conjugate (TAC; Figure $1 \mathrm{~K}$ ) with specificities for the Fc gamma receptor I (CD64), EGFR and the HER2/neu antigen has been developed to redirect cytotoxicity of CD64-bearing effector cells such as macrophages and cytokine-stimulated neutrophilic granulocytes towards cancer cells expressing these tumor-antigens. The TAC interacted more efficiently with the combination of these antigens in cell-binding assays and mediated stronger cytolysis of tumor cells expressing both EGFR and HER2/neu than the corresponding bispecific conjugates directed against only one of these two targets, respectively [38].

\subsection{Dual-Targeting Ligand-Directed-Toxins and Antibody-Drug Conjugates}

The last group of dual-targeting agents presented here comprises toxins fused to antibody-fragments or natural receptor ligands. So far, two different toxin-fragments were used for the generation of dualtargeting agents, the truncated version of Pseudomonas Exotoxin A (ETA'), and a large N-terminal 
fragment of Diphtheria toxin, $\mathrm{DT}_{390}$. Oh and co-workers developed two ligand-directed toxins for the treatment of pancreatic cancer. Both molecules targeted the EGFR and one interleukin receptor (IL-R), either the IL-4R or the IL-13R, respectively, and carried an Exotoxin A fragment as the effector. After binding and internalization, Pseudomonas Exotoxin A modifies the translation elongation factor EF2, leading to the inhibition of translation and apoptosis. In xenograft models the ligand-directed toxins were effective against transplanted pancreatic cancer cells and selectively prevented the formation of metastases [39,40,52]. As an example for use of the second toxin, a bispecific immunotoxin called DT2219ARL, consisting of two scFvs recognizing CD19 and CD22 and the catalytic DT 390 fragment as the death effector, showed strong in vivo anti-leukemic activity in a xenograft murine model. Treatment of transplanted mice with this agent resulted in long-term tumor-free survival, measured in a bioluminescent xenograft imaging model, in which the propagation of Raji Burkitt's lymphoma cells was tracked in real time [41].

\section{Conclusions}

The ultimate goal of cancer therapy can be defined as the search for a treatment, which combines a maximal toxic effect to the tumor with a minimum of therapy-related side effects. Therefore different strategies were pursued, e.g., chemotherapy combined with an antibody-based therapy. The concept of dual targeting is a major deviation from the mono-specific targeting of antibodies in current use for cancer therapy, and it may provide a qualitatively new means to selectively or preferentially target cancer cells. Presented here is a diverse set of recombinant antibody-formats, modified antibodies and ligand-directed toxins, which all share the unique feature of dual-targeting. These new agents will provide a new era of targeted-therapy on the basis of selectivity and specificity resulting in a better drug tolerability and safety thereby preserving and/or improving the cancer patient's quality of life, and in increasing long-lasting response rates with the potential of curing the cancer patient from his/her life-threatening disease.

\section{Acknowledgements}

The authors thank Domenica Saul, Stefanie Nowecki and Barbara Bock for technical assistance, Andreas Mackensen, Bernhard Stockmeyer and Fuat Oduncu for providing primary cells from AML patients and valuable clinical information, and Donata Wehr and Brigitte Woelfel for administrative assistance and Todd Braciak for constructive comments on the manuscript. This research was supported by grants from the DFG (Deutsche Forschungsgesellschaft) to G.H.F. (SFB 643 project 6) and A.M. (SFB 643 project 8), a research grant No. 2007.049. from the Wilhelm Sander Foundation, Neustadt, Germany to G.H.F and B.S., and support from the Stiftung Deutsche Krebshilfe (project No. 08 42) as well as the Association 'Kaminkehrer helfen krebskranken Kindern' (Chimney Sweeps support children with cancer) to G.H.F. Reprint of Figures 3 and 4 kindly permitted by British Journal of Haematology (Wiley-Blackwell), reprint of Figure 5 permitted by mAbs (Landes Bioscience), respectively. 


\section{References and Notes}

1. Adams, G.P.; Weiner, L.M. Monoclonal antibody therapy of cancer. Nat. Biotechnol. 2005, 23, 1147-1157.

2. Duebel, S. Handbook of Therapeutic Antibodies; Wiley-VCH Verlag GmbH \& Co. KGaA: Weinheim, Germany, 2007.

3. Weiner, L.M.; Dhodapkar, M.V.; Ferrone, S. Monoclonal antibodies for cancer immunotherapy. Lancet 2009, 373, 1033-1040.

4. Bargou, R.; Leo, E.; Zugmaier, G.; Klinger, M.; Goebeler, M.; Knop, S.; Noppeney, R.; Viardot, A.; Hess, G.; Schuler, M.; et al. Tumor regression in cancer patients by very low doses of a T cell-engaging antibody. Science 2008, 321, 974-977.

5. Clynes, R. Antitumor antibodies in the treatment of cancer: Fc receptors link opsonic antibody with cellular immunity. Hematol. Oncol. Clin. North Am. 2006, 20, 585-612.

6. de Haij, S.; Jansen, J.H.; Boross, P.; Beurskens, F.J.; Bakema, J.E.; Bos, D.L.; Martens, A.; Verbeek, J.S.; Parren, P.W.; van de Winkel, J.G.; et al. In vivo cytotoxicity of type I CD20 antibodies critically depends on Fc receptor ITAM signaling. Cancer Res. 2010, 70, 3209-3217.

7. Heiss, M.M.; Murawa, P.; Koralewski, P.; Kutarska, E.; Kolesnik, O.O.; Ivanchenko, V.V.; Dudnichenko, A.S.; Aleknaviciene, B.; Razbadauskas, A.; Gore, M.; et al. The trifunctional antibody catumaxomab for the treatment of malignant ascites due to epithelial cancer: Results of a prospective randomized phase II/III trial. Int. J. Cancer 2010, 127, 2209-2221.

8. Musolino, A.; Naldi, N.; Bortesi, B.; Pezzuolo, D.; Capelletti, M.; Missale, G.; Laccabue, D.; Zerbini, A.; Camisa, R.; Bisagni, G.; et al. Immunoglobulin G fragment $\mathrm{C}$ receptor polymorphisms and clinical efficacy of trastuzumab-based therapy in patients with HER-2/neupositive metastatic breast cancer. J. Clin. Oncol. 2008, 26, 1789-1796.

9. Zhang, W.; Gordon, M.; Schultheis, A.M.; Yang, D.Y.; Nagashima, F.; Azuma, M.; Chang, H.M.; Borucka, E.; Lurje, G.; Sherrod, A.E.; et al. FCGR2A and FCGR3A polymorphisms associated with clinical outcome of epidermal growth factor receptor expressing metastatic colorectal cancer patients treated with single-agent cetuximab. J. Clin. Oncol. 2007, 25, 3712-3718.

10. Kellner, C.; Bruenke, J.; Stieglmaier, J.; Schwemmlein, M.; Schwenkert, M.; Singer, H.; Mentz, K.; Peipp, M.; Lang, P.; Oduncu, F.; et al. A novel CD19-directed recombinant bispecific antibody derivative with enhanced immune effector functions for human leukemic cells. J. Immunother. 2008, 31, 871-884.

11. Kugler, M.; Stein, C.; Kellner, C.; Mentz, K.; Saul, D.; Schwenkert, M.; Schubert, I.; Singer, H.; Oduncu, F.; Stockmeyer, B.; et al. A recombinant trispecific single-chain Fv derivative directed against CD123 and CD33 mediates effective elimination of acute myeloid leukaemia cells by dual targeting. Br. J. Haematol. 2010, 150, 574-586.

12. Schubert, I.; Kellner, C.; Stein, C.; Kugler, M.; Schwenkert, M.; Saul, D.; Berens, C.; Oduncu, F.; Stockmeyer, B.; Mackensen, A.; et al. A recombinant triplebody with specificity for CD19 and HLA-DR mediates preferential binding to antigen double-positive cells by dual-targeting. $m A b s$ 2012, 4, 45-56. 
13. Schubert, I.; Kellner, C.; Stein, C.; Kugler, M.; Schwenkert, M.; Saul, D.; Mentz, K.; Singer, H.; Stockmeyer, B.; Hillen, W.; et al. A single-chain triplebody with specificity for CD19 and CD33 mediates effective lysis of mixed lineage leukemia cells by dual targeting. MAbs 2011, 3, 21-30.

14. Topp, M.S.; Kufer, P.; Gokbuget, N.; Goebeler, M.; Klinger, M.; Neumann, S.; Horst, H.A.; Raff, T.; Viardot, A.; Schmid, M.; et al. Targeted therapy with the T-cell-engaging antibody blinatumomab of chemotherapy-refractory minimal residual disease in B-lineage acute lymphoblastic leukemia patients results in high response rate and prolonged leukemia-free survival. J. Clin. Oncol. 2011, 29, 2493-2498.

15. Topp, M,G.N.; Kufer, P.; Zugmaier, G.; Degenhard, E.; Neumann, S.; Horst, H.A.; Viardot, A.; Schmid, M.; Ottmann, O.G.; Schmidt, M.; et al. Treatment with anti-CD19 BiTE antibody bli $\neg$ natumomab (MT103/MEDI-538) is able to eliminate minimal residual disease (MRD) in patients with B-precursor acute lmphoblastic leukemia (ALL): First results of an ongoing phase II study (ASH Annual Meeting Abstract). Blood 2008, 112, 1926.

16. Bluemel, C.; Hausmann, S.; Fluhr, P.; Sriskandarajah, M.; Stallcup, W.B.; Baeuerle, P.A.; Kufer, P. Epitope distance to the target cell membrane and antigen size determine the potency of $\mathrm{T}$ cellmediated lysis by BiTE antibodies specific for a large melanoma surface antigen. Cancer Immunol. Immunother. 2010, 59, 1197-1209.

17. Huhalov, A.; Chester, K.A. Engineered single chain antibody fragments for radioimmunotherapy. Q. J. Nucl. Med. Mol. Imaging. 2004, 48, 279-288.

18. Kipriyanov, S.M.; Moldenhauer, G.; Schuhmacher, J.; Cochlovius, B.; Von der Lieth, C.W.; Matys, E.R.; Little, M. Bispecific tandem diabody for tumor therapy with improved antigen binding and pharmacokinetics. J. Mol. Biol. 1999, 293, 41-56.

19. Raghavan, M.; Chen, M.Y.; Gastinel, L.N.; Bjorkman, P.J. Investigation of the interaction between the class I MHC-related Fc receptor and its immunoglobulin G ligand. Immunity 1994, 1, 303-315.

20. Kubetzko, S.; Balic, E.; Waibel, R.; Zangemeister-Wittke, U.; Pluckthun, A. PEGylation and multimerization of the anti-p185HER-2 single chain Fv fragment 4D5: Effects on tumor targeting. J. Biol. Chem. 2006, 281, 35186-35201.

21. Schoonjans, R.; Willems, A.; Schoonooghe, S.; Fiers, W.; Grooten, J.; Mertens, N. Fab chains as an efficient heterodimerization scaffold for the production of recombinant bispecific and trispecific antibody derivatives. J. Immunol. 2000, 165, 7050-7057.

22. Muller, D.; Karle, A.; Meissburger, B.; Hofig, I.; Stork, R.; Kontermann, R.E. Improved pharmacokinetics of recombinant bispecific antibody molecules by fusion to human serum albumin. J. Biol. Chem. 2007, 282, 12650-12660.

23. Kontermann, R.E. Strategies for extended serum half-life of protein therapeutics. Curr. Opin. Biotechnol. 2011, 22, 868-876.

24. Ring, D.B.; Hsieh-Ma, S.T.; Shi, T.; Reeder, J. Antigen forks: bispecific reagents that inhibit cell growth by binding selected pairs of tumor antigens. Cancer Immunol. Immunother. 1994, 39, 41-48.

25. Tuscano, J.M.; Ma, Y.; Martin, S.M.; Kato, J.; O'Donnell, R.T. The Bs20x22 anti-CD20-CD22 bispecific antibody has more lymphomacidal activity than do the parent antibodies alone. Cancer Immunol. Immunother. 2011, 60, 771-780. 
26. Robinson, M.K.; Hodge, K.M.; Horak, E.; Sundberg, A.L.; Russeva, M.; Shaller, C.C.; von Mehren, M.; Shchaveleva, I.; Simmons, H.H.; Marks, J.D.; et al. Targeting ErbB2 and ErbB3 with a bispecific single-chain Fv enhances targeting selectivity and induces a therapeutic effect in vitro. Br. J. Cancer 2008, 99, 1415-1425.

27. Gupta, P.; Goldenberg, D.M.; Rossi, E.A.; Cardillo, T.M.; Byrd, J.C.; Muthusamy, N.; Furman, R.R.; Chang, C.H. Dual-targeting immunotherapy of lymphoma: potent cytotoxicity of antiCD20/CD74 bispecific antibodies in mantle cell and other lymphomas. Blood 2012, Epub ahead of print.

28. Schaefer, G.; Haber, L.; Crocker, L.M.; Shia, S.; Shao, L.; Dowbenko, D.; Totpal, K.; Wong, A.; Lee, C.V.; Stawicki, S.; et al. A two-in-one antibody against HER3 and EGFR has superior inhibitory activity compared with monospecific antibodies. Cancer Cell 2011, 20, 472-486.

29. Dong, J.; Sereno, A.; Aivazian, D.; Langley, E.; Miller, B.R.; Snyder, W.B.; Chan, E.; Cantele, M.; Morena, R.; Joseph, I.B.; et al. A stable IgG-like bispecific antibody targeting the epidermal growth factor receptor and the type I insulin-like growth factor receptor demonstrates superior anti-tumor activity. MAbs 2011, 3, 273-288.

30. McDonagh, C.F.; Huhalov, A.; Harms, B.D.; Adams, S.; Paragas, V.; Oyama, S.; Zhang, B.; Luus, L.; Overland, R.; Nguyen, S.; et al. Antitumor activity of a novel bispecific antibody that targets the ErbB2/ErbB3 oncogenic unit and inhibits heregulin-induced activation of ErbB3. Mol. Cancer Ther. 2012, 11, 582-593.

31. Lu, D.; Kotanides, H.; Jimenez, X.; Zhou, Q.; Persaud, K.; Bohlen, P.; Witte, L.; Zhu, Z. Acquired antagonistic activity of a bispecific diabody directed against two different epitopes on vascular endothelial growth factor receptor 2. J. Immunol. Methods 1999, 230, 159-171.

32. Jimenez, X.; Lu, D.; Brennan, L.; Persaud, K.; Liu, M.; Miao, H.; Witte, L.; Zhu, Z. A recombinant, fully human, bispecific antibody neutralizes the biological activities mediated by both vascular endothelial growth factor receptors 2 and 3. Mol. Cancer Ther. 2005, 4, 427-434.

33. Emanuel, S.L.; Engle, L.J.; Chao, G.; Zhu, R.R.; Cao, C.; Lin, Z.; Yamniuk, A.P.; Hosbach, J.; Brown, J.; Fitzpatrick, E.; et al. A fibronectin scaffold approach to bispecific inhibitors of epidermal growth factor receptor and insulin-like growth factor-I receptor. MAbs 2011, 3, 38-48.

34. Doppalapudi, V.R.; Huang, J.; Liu, D.; Jin, P.; Liu, B.; Li, L.; Desharnais, J.; Hagen, C.; Levin, N.J.; Shields, M.J.; et al. Chemical generation of bispecific antibodies. Proc. Natl. Acad. Sci. USA 2010, 107, 22611-22616.

35. Mabry, R.; Gilbertson, D.G.; Frank, A.; Vu, T.; Ardourel, D.; Ostrander, C.; Stevens, B.; Julien, S.; Franke, S.; Meengs, B.; et al. A dual-targeting PDGFRbeta/VEGF-A molecule assembled from stable antibody fragments demonstrates anti-angiogenic activity in vitro and in vivo. MAbs 2010, 2, 20-34.

36. Wu, C.; Ying, H.; Bose, S.; Miller, R.; Medina, L.; Santora, L.; Ghayur, T. Molecular construction and optimization of anti-human IL-1alpha/beta dual variable domain immunoglobulin (DVD-Ig) molecules. MAbs 2009, 1, 339-347.

37. Bhattacharyya, S.; Khan, J.A.; Curran, G.L.; Robertson, J.D.; Bhattacharya, R.; Mukherjee, P. Efficient delivery of gold nanoparticles by dual receptor targeting. Adv. Mater. 2011, 23, 5034-5038. 
38. Somasundaram, C.; Sundarapandiyan, K.; Keler, T.; Deo, Y.M.; Graziano, R.F. Development of a trispecific antibody conjugate that directs two distinct tumor-associated antigens to CD64 on myeloid effector cells. Hum. Antibodies 1999, 9, 47-54.

39. Oh, S.; Stish, B.J.; Sachdev, D.; Chen, H.; Dudek, A.Z.; Vallera, D.A. A novel reduced immunogenicity bispecific targeted toxin simultaneously recognizing human epidermal growth factor and interleukin-4 receptors in a mouse model of metastatic breast carcinoma. Clin. Cancer Res. 2009, 15, 6137-6147.

40. Oh, S.; Stish, B.J.; Vickers, S.M.; Buchsbaum, D.J.; Saluja, A.K.; Vallera, D.A. A new drug delivery method of bispecific ligand-directed toxins, which reduces toxicity and promotes efficacy in a model of orthotopic pancreatic cancer. Pancreas 2010, 39, 913-922.

41. Vallera, D.A.; Chen, H.; Sicheneder, A.R.; Panoskaltsis-Mortari, A.; Taras, E.P. Genetic alteration of a bispecific ligand-directed toxin targeting human CD19 and CD22 receptors resulting in improved efficacy against systemic B cell malignancy. Leuk. Res. 2009, 33, 1233-1242.

42. Hurwitz, S.J.; Zhang, H.; Yun, S.; Batuwangala, T.D.; Steward, M.; Holmes, S.D.; Rycroft, D.; Pan, L.; Tighiouart, M.; Shin, H.J.; et al. Pharmacodynamics of DT-IgG, a dual-targeting antibody against VEGF-EGFR, in tumor xenografted mice. Cancer Chemother. Pharmacol. 2011, 69, 577-590.

43. Kontermann, R.E. Bispecific Antibodies, 1st ed.; Springer-Verlag Berlin: Heidelberg, Germany, 2011; p. 373.

44. Brinkmann, U.; Reiter, Y.; Jung, S.H.; Lee, B.; Pastan, I. A recombinant immunotoxin containing a disulfide-stabilized Fv fragment. Proc. Natl. Acad. Sci. USA 1993, 90, 7538-7542.

45. Jordan, C.T.; Upchurch, D.; Szilvassy, S.J.; Guzman, M.L.; Howard, D.S.; Pettigrew, A.L.; Meyerrose, T.; Rossi, R.; Grimes, B.; Rizzieri, D.A.; et al. The interleukin-3 receptor alpha chain is a unique marker for human acute myelogenous leukemia stem cells. Leukemia 2000, 14, 1777-1784.

46. Taussig, D.C.; Pearce, D.J.; Simpson, C.; Rohatiner, A.Z.; Lister, T.A.; Kelly, G.; Luongo, J.L.; Danet-Desnoyers, G.A.; Bonnet, D. Hematopoietic stem cells express multiple myeloid markers: implications for the origin and targeted therapy of acute myeloid leukemia. Blood 2005, 106, 4086-4092.

47. Singer, H.; Kellner, C.; Lanig, H.; Aigner, M.; Stockmeyer, B.; Oduncu, F.; Schwemmlein, M.; Stein, C.; Mentz, K.; Mackensen, A.; et al. Effective elimination of acute myeloid leukemic cells by recombinant bispecific antibody derivatives directed against CD33 and CD16. J. Immunother. 2010, 33, 599-608.

48. Kugler, M.; Stein, C.; Schwenkert, M.; Saul, D.; Vockentanz, L.; Huber, T.; Wetzel, S.K.; Scholz, O.; Pluckthun, A.; Honegger, A.; et al. Stabilization and humanization of a single-chain Fv antibody fragment specific for human lymphocyte antigen CD19 by designed point mutations and CDR-grafting onto a human framework. Protein Eng. Des. Sel. 2009, 22, 135-147.

49. Armstrong, S.A.; Look, A.T. Molecular genetics of acute lymphoblastic leukemia. J. Clin. Oncol. 2005, 23, 6306-6315.

50. Hrusak, O.; Porwit-MacDonald, A. Antigen expression patterns reflecting genotype of acute leukemias. Leukemia 2002, 16, 1233-1258. 
51. Schubert, I. University of Erlangen-Nuremberg, Erlangen, Germany. Unpublished work, 2012.

52. Oh, S.; Todhunter, D.A.; Panoskaltsis-Mortari, A.; Buchsbaum, D.J.; Toma, S.; Vallera, D.A. A deimmunized bispecific ligand-directed Toxin that shows an impressive anti-pancreatic cancer effect in a systemic nude mouse orthotopic model. Pancreas 2012, Epub ahead of print.

(C) 2012 by the authors; licensee MDPI, Basel, Switzerland. This article is an open access article distributed under the terms and conditions of the Creative Commons Attribution license (http://creativecommons.org/licenses/by/3.0/). 